\title{
A case of guidewire embolism during central venous catheterization: Better safe than sorry!
}

\begin{abstract}
Sir,
Central venous catheterization (CVC) is a routine procedure in intensive care unit as well as in surgical patients requiring monitoring of hemodynamic variables, for medications and parentral nutrition, hemodialysis etc. The incidence of complications ranges from $5 \%$ to $29 \%{ }^{[1]}$ such as arterial puncture, hemothorax, pneumothorax, nerve injury, air embolism or dysrthythmias. Guidewire embolism during CVC is a rare iatrogenic complication. ${ }^{[2]}$ The Seldinger technique is commonly used to cannulate the vessels. ${ }^{[3]}$ We report a case of lost guidewire following
\end{abstract}




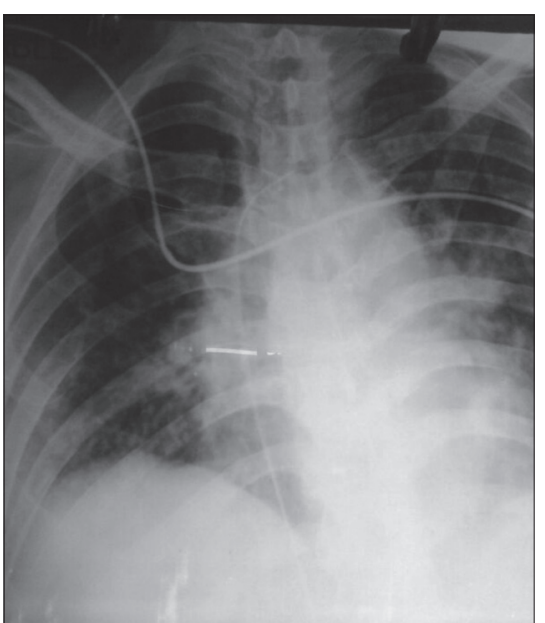

Figure I: Chest $\mathrm{X}$-ray showing guidewire

internal jugular catheter placement and its successful management.

A 64-year-old male, weighing $67 \mathrm{~kg}, 176 \mathrm{~cm}$ height had c/o hematuria since last 15 days. Patient was suffering from chronic obstructive pulmonary disease, diabetes and hypertension. Ultrasound showed bladder mass lesion, enlarged prostate, and hepatomegaly. His serum creatinine was $5.07 \mathrm{mg} / \mathrm{dl}$, total cholesterol-18,170/cmm, serum glutamic-pyruvic transaminase-122.0 and serum glutamic oxaloacetic transaminase-118.0. In view of acute renal failure and septicemia, CVC for fluid management and drug administration was advised. During a busy night shift, a $2^{\text {nd }}$ year resident was assigned to perform the procedure. The left internal jugular vein was cannulated using double lumen (Polymed Novocent Duo, $160 \mathrm{~mm}$ ) polyurethane catheter by central approach after local infiltration, under ultrasound guidance. A J-tipped guidewire $(0.035 \mathrm{~mm}, 50 \mathrm{~cm})$ was introduced through the needle followed by dilatation of the tract with a dilator ( $8.5 \mathrm{Fr}, 4$ inches) and insertion of the catheter on the guidewire. During this procedure, the guidewire was inadvertently pushed further ahead into the vein. This went unnoticed by the resident, who tried to aspirate blood from both the lumen to confirm proper positioning of the catheter. Due to inability to aspirate free flow of blood from one of the lumen, the resident flushed saline through that lumen, which could have resulted in embolization of the guidewire. After completion of the procedure, he realized that the guidewire was missing and informed the seniors. An urgent chest $X$-ray [Figure 1] and X-ray kidneys, ureters, and bladder [Figure 2] were done in which guidewire was clearly visible. It was removed by gooseneck snare device through femoral percuteneous approach under local anesthesia and fluoroscopic guidance without any complication.

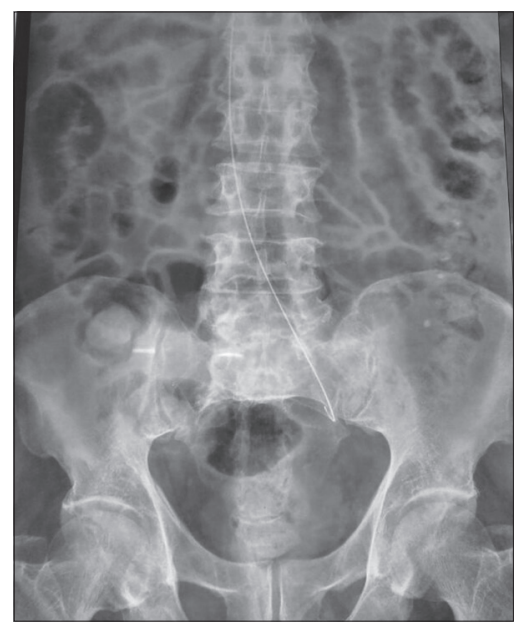

Figure 2: X-ray kidneys, ureters, and bladder showing embolized guidewire

For the management of guidewire embolism, if the guidewire has embolized systemically, chest X-ray and if required X-ray abdomen will determine the position of the guidewire. The percutaneous method of extraction has fewer complications for which interventional radiology techniques such as dormia basket, gooseneck snare, endovascular forceps are preferable. ${ }^{[4]}$ Cheddie and Sing ${ }^{[5]}$ describe a similar approach for guidewire extraction using a goose snare device.

Our take home massage is that, the complications of CVC should be kept in mind during cannulation. The guidewire should not be inserted too far as average distance from all access site is $18 \mathrm{~cm}$. One should hold the guidewire tip firmly while introducing the catheter and should check the guidewire outside before flushing the percutaneous catheter. Without free flow of blood during aspiration, one should not flush the catheter. Gooseneck snare technique is safe for removal of embolized guidewire.

Geeta P. Parikh, Sumedha Shonde, Rajkiran Shah, Nirav Kharadi Department of Anaesthesia and Critical Care, Smt. K. M. Mehta and Smt. G. R. Doshi Institute of Kidney Diseases and Research Center Dr. H. L. Trivedi Institute of Transplantation Sciences, Asarwa, Ahmedabad, Gujarat, India

Correspondence: Dr. Geeta P. Parikh,
28/Yogashram Society, Near Shyamal Char Rasta, Ahmedabad - 380 015, Gujarat, India. E-mail: gpp2011@live.in

\section{References}

1. Eisen LA, Narasimhan M, Berger JS, Mayo PH, Rosen MJ, Schneider RF. Mechanical complications of central venous catheters. J Intensive Care Med 2006;21:40-6.

2. Schummer W, Schummer C, Gaser E, Bartunek R. Loss of the guide wire: Mishap or blunder? Br J Anaesth 2002;88:144-6.

3. Seldinger SI. Catheter replacement of the needle in percutaneous arteriography; a new technique. Acta radiol 1953;39:368-76. 
4. Roye GD, Breazeale EE, Byrnes JP, Rue LW $3^{\text {rd }}$. Management of catheter emboli. South Med J 1996;89:714-7.

5. Cheddie S, Sing B. Guidewire embolism during central venous catheterization: Options in management. Internet J Surg 2013;30:1.

\begin{tabular}{|l|l|}
\hline \multicolumn{2}{|c|}{ Access this article online } \\
\hline Quick Response Code: & Website: \\
\hline & www.jiccm.org \\
\cline { 2 - 2 } & Dol: 10.4103/0972-5229.146340 \\
\hline
\end{tabular}

